\title{
Bioseguridad en la atención odontológica ante la pandemia COVID-19
}

\section{Carta al Editor}

\author{
Karina Perez-Muñante 1,a, Grace Quintanilla-Ramos ${ }^{1, a}$, \\ Kamila Sihuay-Torres ${ }^{2, b}$ \\ ${ }^{1}$ Universidad Nacional San Luis Gonzaga, Facultad de \\ Odontología, Ica, Perú. \\ 2 Universidad Nacional Mayor de San Marcos, Facultad \\ de Odontología, Lima, Perú. \\ a Estudiante de Odontología. \\ ${ }^{\mathrm{b}}$ Cirujano Dentista.
}

\section{Biosecurity in dental care for the COVID-19 pandemic}

\section{Sr. Editor.}

La COVID-19 (SARS-CoV 2), nos ha llevado a un nuevo estilo de vida, con diversos métodos de protección para evitar el contagio. El campo odontológico es uno de los más expuestos, ya que el principal método de transmisión es a través de la saliva. Por este motivo, los odontólogos han buscado nuevas modalidades de atención para evitar la propagación de dicho virus, las cuales se van actualizando constantemente. De esta forma, la presente carta tiene como objetivo actualizar al odontólogo con las nuevas medidas de bioseguridad durante la atención odontológica.

Antes de iniciar una consulta, evaluar si es necesario la atención física o si se puede postergar aliviando la molestia con alguna medicación. En ese sentido, el uso de la teleodontología es una opción. Sin embargo, es limitada ya que consideramos que no se puede llegar a un diagnóstico definitivo y por ende a un plan de tratamiento. Se debe tener cuidado al brindar alguna prescripción farmacológica para evitar que se ponga en riesgo la salud general del paciente. Si se opta por una atención presencial, se debe realizar un cuestionario al paciente sobre signos y síntomas relacionados a la COVID-19. Esto incluye preguntas relacionadas a si ha tenido tos, fiebre superior a $37,5^{\circ} \mathrm{C}$, dolor de garganta, o algún contacto con una persona confirmada o sospechosa de tener la enfermedad ${ }^{1,2}$. Si el paciente requiere atención presencial debe ser consciente del riesgo de contaminación cruzada al que podría estar expuesto, por eso debe firmar un consentimiento informado, antes de que se le realice algún procedimiento ${ }^{3}$.

Para la consulta presencial, el consultorio, sala de espera, baño y otros espacios que estén en contacto con el paciente y personal de atención, deben tener medidas adecuadas de desinfección y ventilación, antes y después de su uso. Cabe resaltar que la presencia del virus permanece hasta 9 días en las superficies según su material ${ }^{1,3-5}$. Debemos considerar el uso de desinfectantes para superficies, como el hipoclorito de sodio a

\section{Correspondencia:}

Grace Quintanilla-Ramos: 20161828@unica.edu.pe

Dirección: Resid. San Carlos Mnza G It 30.

ORCID : 0000-0002-0132-2293

\section{Coautores:}

Karina Perez-Muñante: 20161826@unica.edu.pe ORCID: 0000-0002-4392-046X

Kamila Sihuay-Torres: kamila.sihuay28@gmail.com ORCID: 0000-0001-5247-2454

Conflicto de intereses: Los autores declaran no tener conflicto de intereses.

Recibido: $11 / 11 / 20$

Aprobado: $23 / 11 / 20$

Publicado: 15/02/21 
una concentración mínima de $0,21 \%$ hasta $0,5 \%$ o alcohol de $62 \%$ hasta $71 \%$. También se recomienda el uso de amonio cuaternario de quinta generación según las indicaciones del fabricante ${ }^{1-4}$. Actualmente se está considerando la irradiación germicida ultravioleta (UVGI) por sus buenos resultados ${ }^{3}$.

Antes de la atención odontológica es importante el uso previo de antisépticos orales. Se recomienda usar enjuagues bucales a base de cloruro de cetil piridinio al $0,05 \%$, clorhexidina al $0,12 \%$ y yodo povidona al $0,2 \%-1 \%{ }^{1,4}$. Por otro lado, el odontólogo y asistente deben usar un adecuado equipo de protección personal (EPP) que incluye respiradores con un 95\% de capacidad de filtración como mínimo (FFP2, FFP3, N95 o KN95), evitando las mascarillas quirúrgicas convencionales. Así mismo, deben usar guantes de examen, lentes de protección con ventosas (para un adecuado sellado al rostro), protector facial, mandilón y zapatos impermeables que puedan desinfectarse fácilmente ${ }^{1-4}$. El retiro del EPP debe ser con precaución, evitando el contacto con las superficies posiblemente contaminadas.

Durante los procedimientos odontológicos, se recomienda el uso de radiografías extraorales para evitar reflejos nauseosos o tos. En caso se requiera una radiografía intraoral, se recomienda usar posicionadores teniendo los cuidados necesarios. Es importante reducir las intervenciones con instrumental rotatorio de alta velocidad, ultrasonido y jeringa triple. Solo en las situaciones que amerite su uso, usar aislamiento absoluto. Además, se recomienda usar un equipo de alta succión, ya que el sistema de succión convencional no es suficientemente capaz de eliminar los aerosoles ${ }^{1-3}$. También, se sugiere la participación de más de un asistente, para evitar la contaminación cruzada durante procedimientos como el llenado de historia clínica, toma de impresiones, toma de radiografía, entre otros ${ }^{5}$. Para evitar citas presenciales de post-tratamiento como el retiro de suturas, se sugiere utilizar suturas reabsorbibles, hacer seguimiento a través de videollamadas y hacer una correcta medicación antibiótica y antiinflamatoria ${ }^{4}$.

Por otro lado, la impresión convencional se puede reemplazar por el uso de tecnología CAD/CAM ${ }^{2}$. Sin embargo, no es accesible para todos, por lo que la impresión de alginato o algún elastómero se deben limpiar y desinfectar correctamente. La limpieza se debe realizar con agua jabonosa frotada con pincel y enjuagar. Luego, para la desinfección de impresiones con alginato, rociar con hipoclorito de sodio al $1 \%$ y dejar actuar por 10 min para después enjuagar. Para las impresiones con elastómeros, se usará el hipoclorito de sodio al 1\% durante 15 a $20 \mathrm{~min}$, y finalmente enjuagar con agua ${ }^{3}$.

Basados en esta información, podemos concluir que el uso de todas estas medidas de bioseguridad son necesarias para evitar la contaminación cruzada, así como para cuidar la salud de todo el personal que trabaja dentro del consultorio odontológico. Estas medidas se van actualizando conforme la enfermedad siga vigente, por lo que los odontólogos tienen el deber de estar constantemente actualizados.

\section{Referencias bibliográficas}

1. Araya S. Consideraciones para la atención de urgencia odontológica y medidas preventivas para COVID-19 (SARS-CoV 2). Int J Odontostomat [Internet]. 2020 [citado el 03 de julio del 2020];14(3):268-270. Disponible en: http://www.ijodontostomatology.com/es/articulo/ consideraciones-para-la-atencion-de-urgencia-odontologica-y-medidas-preventivas-para-covid-19-sars-cov-2/

2. Cayo-Rojas C, Baltazar-Sanchez AC. Recomendaciones clínicas odontológicas frente al COVID-19, de acuerdo con la evidencia científica. Rev Habanera Cienc Médi [Internet]. 2020 [citado el 03 de julio del 2020];19(2):e3283. Disponible en: http://www.revhabanera.sld.cu/index.php/rhab/article/view/3283

3. Sigua-Rodriguez EA, Benal-Perez JL, Lanata-Flores AG, Sanchez-Romero C, Rodriguez-Chessa J, Haidar ZS, et al. Covid-19 y la odontología: Una revisión de las recomendaciones y las perspectivas para latinoamérica. Int J Odontostomat [Internet]. 2020 [citado el 13 de julio del 2020];14(3):299-309. Disponible en: http://www.ijodontostomatology.com/es/articulo/covid-19-y-la-odontologia-una-revision-de-las-recomendaciones-y-perspectivas-para-latinoamerica/

4. Sepúlveda VV, Secchi AA, Donoso-Hofer F. Consideraciones en la atención odontológica de urgencia en contexto de coronavirus COVID-19 (SARS-CoV-2). Int J Odontostomat [Internet]. 2020 [citado el 23 de julio del 2020];14(3):279-284. Disponible en: http://www. ijodontostomatology.com/es/articulo/consideraciones-en-la-atencion-odontologica-de-urgencia-en-contexto-de-coranovirus-covid-19-sars-cov-2/

5. Verdera S. Protocolo de Atención en Odontología Restauradora ante la emergencia sanitaria Covid-19. Odontoestomatología [Internet]. 2020 [citado el 26 de julio del 2020];22(especial):67-8. Disponible en: https:// odon.edu.uy/ojs/index.php/ode/article/view/300 